\title{
Estudo comparativo de tratamento da estomatite protética pelo reembasamento ou substituição das próteses totais*
}

\author{
Comparative study on the treatment of denture stomatitis through relining or \\ replacement of full dentures
}

Luiz Fernando W alber ${ }^{* *}$

RESUMO

Este estudo clínico buscou comparar duas formas de tratamento para pacientes que fossem portadores de próteses totais superiores e apresentassem clinicamente a Estomatite Protética. Foram selecionados 30 pacientes divididos em dois grupos. O grupo I foi constituído de 18 pacientes que tiveram suas próteses substituídas por novas. $O$ grupo II foi constituído por 12 pacientes onde foi realizado o reembasamento das próteses totais em uso. Os pacientes foram acompanhados por um período de 8 semanas. Em ambos os grupos foi solicitado aos pacientes que removessem a prótese à noite para a desinfecção com solução de hipoclorito de sódio. Os resultados mostraram a cura da Estomatite Protética num prazo de 4 semanas numa proporção de $90 \%$, para os dois grupos sem diferença estatisticamente significante. Foi possível concluir que, tanto a substituição da prótese como o seu reembasamento associados à higiene e a desinfecção mostraram-se eficazes no controle da Estomatite Protética.

UNITERMOS

Estomatite Protética, Prótese Total, Patologia Bucal

\section{INTRODUÇÃO}

A Estomatite Protética é uma patologia comum em pacientes portadores de próteses totais e parciais removíveis (CAHN,1936; NYQUIST,1952;CAWSON,1963; BUDTZJÖRGENSEN \& BERTRAM, 1970; BALÁEZ \& DÍAZ, 1985; KOOPMANS et al., 1988;e ALLEN, 1992). A forma de tratamento de preferência tem sido o uso de antifúngicos, especialmente entre aqueles que atribuem à Cândida albicans, a causa etiológica. No entanto, BUDTZ-JÖRGENSE \& BERTRAM(1970b), BERGENDAL \& ISACSSON(1980) nos mostram que o tratamento com nistatina, embora produza uma significativa redução do eritema da mucosa palatina, não cura a Estomatite Protética.

O objetivo deste trabalho é o de revisar as informações relativas ao assunto e comparar a efetividade dos métodos de tratamento por substituição da prótese com reembasamento da prótese em uso.

\section{REVISÃO DA LITERATURA}

Pacientes portadores de próteses mucossuportadas, tanto parciais quanto próteses totais, freqüentemente apresentam alterações patológicas da mucosa de suporte. Dentre as alterações mais comuns destacam- se, segundo FELTRIN et al.(1993) e BARBACHAN et al.(1995), o aparecimento da hiperemia, edema e inflamação moderada ou intensa destes tecidos. Estas alterações podem se manifestar como uma inflamação localizada numa área limitada ou envolvendo toda a área recoberta pela dentadura (BUDTZJÖRGENSE \& BERTRAM, 1970).

A prevalência exata da Estomatite Protética é variável, dependendo do pesquisador consultado. Os valores oscilam entre 27\% (NYQUIST,1952) e 67\%(BUDTZJÖRGENSEN, 1978).

CAWSON(1963), BUDTZ-JÖRGENSE \& BERTRAM(1970a), relatam que esta condição pode estar à associada à queilite angular e a glossite.

GROS et al.(1990) referem a ausência da percepção da sintomatologia na Estomatite Protética e afirmam que, em numerosas ocasiões, a descoberta da mesma ocorre através de um exame de rotina pelo cirurgiãodentista.

$\hat{E}$ aceito por vários autores como NEWTON(1962), CAWSON(1963), LOVE et al.(1967), DIAZ(1989), JEGANATHAN(1992), FELTRIN et al.(1993), ZANETTI et al.(1996) que a Estomatite Protética se manifesta preferencialmente no maxilar superior, sobretudo no palato, sendo raro na mucosa do rebordo alveolar inferior. Também tem sido observada uma maior frequiência nas mulheres do que nos homens (LOVE et al.,1967; MIKKONEN et al., 1984; DIAZ et al., 1989; ZANETTI et al., 1996).

NEWTON(1962) classificou a Estomatite Protética de acordo com três tipos clínicos:

Tipo I: sinais inflamatórios mínimos, geralmente assintomáticos. Mostrando inflamação localizada ou hiperemia puntiforme, usualmente em torno dos orificios dos ductos das glândulas da mucosa palatina.

Tipo II: Mostra uma superfície com áreas eritematosas difusas que podem cobrirse total ou parcialmente por pseudo membrana branca. Geralmente o paciente expressa alguma sensação subjetiva.

Tipo III: Inflamação granular ou hiperplásica papilar. A mucosa tem uma aparência nodular com hiperemia na superfície, sendo mais restrita a área central da mucosa palatina.

A determinação da etiologia da Estomatite Protética é controvertida, pois diversas condições locais ou sistêmicas podem estar envolvidas.

* Resumo da dissertação apresentada para a obtenção do título de Mestre em Odontologia

** Mestre em Odontologia (Prótese Dentária)

*** Doutor em Odontologia (Patologia Bucal) 


\section{ASPECTOS ETIOPATOGÊNICOS:}

Os principais fatores que estão implicados são: trauma, infecção, alergia e condições sistêmicas (CAHN, 1936; RATTNER, 1936; NYQUIST, 1952; BUDTZ-JÖRGENSE \& BERTRAM, 1970a; VAN REENEN, 1973; SABET, 1975; BALÁEZ \& DÍAZ, 1985; JEGANATHAN, 1992).

\section{TRATAMENTO}

Baseado na literatura consultada, a forma de tratamento preconizada pelos trabalhos que se preocupam com a terapêutica da Estomatite Protética, varia de acordo com o enfoque etiológico (DAVENPORT, 1978; BUDTZ-JÖRGENSEN， 1979; JEGANATHAN, 1992).

$\mathrm{O}$ tratamento da Estomatite Protética pode ser obtido através dos seguintes métodos:

2.1. Remoção da fonte de origem

2.2. Correção das falhas da prótese

2.3. Higiene da prótese

2.4. Eliminação da infecção

\section{MATERIAIS E MÉTODOS}

Trinta pacientes buscaram atendimento junto às faculdades de Odontologia da PUCRS e da UFRGS. Os pacientes desdentados superiores, apresentavam sinais clínicos de Estomatite Protética. Para a seleção destes pacientes, foi aplicado um questionário buscando eliminar aqueles que apresentavam doenças de origem sistêmica que pudessem exacerbar o quadro clínico da Estomatite Protética.

A Estomatite Protética foi classificada quanto à sua severidade de acordo com a classificação de NEWTON(1962).

Tipo I: Sinais inflamatórios mínimos, geralmente assintomáticos. Mostram inflamação localizada ou hiperemia puntiforme, usualmente em torno dos orifícios dos ductos das glândulas da mucosa palatina (fotografia 1).

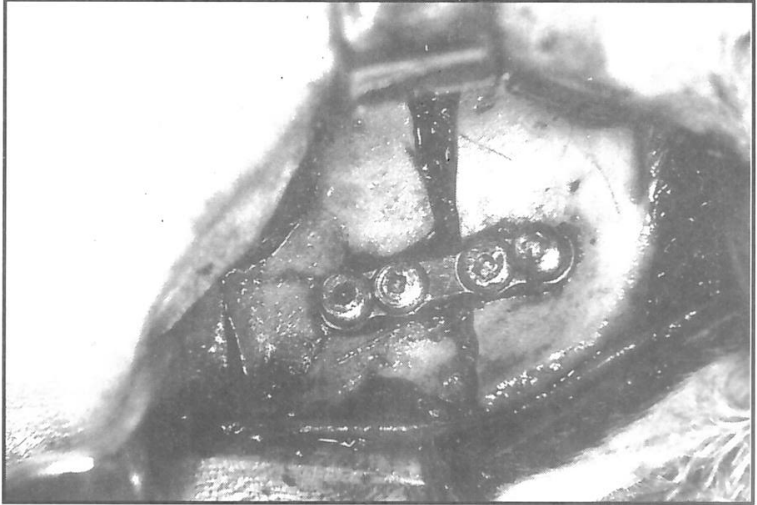

Fotografia. 1 Paciente do gênero feminino, com 54 anos apresentando Estomatite Protética do Tipo I. Foi tratada com o reembasamento da prótese.
Tipo II: Mostra uma superfície com áreas eritematosas difusas que podem cobrir-se total ou parcialmente por pseudo membrana branca. Geralmente o paciente expressa alguma sensação subjetiva (fotografia 2).

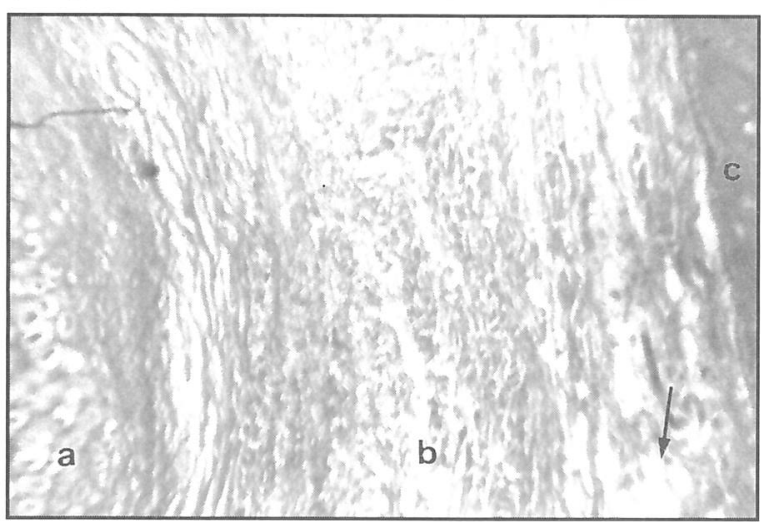

Fotografia. 2. Paciente do gênero ínasculino, com 60 anos apresentando Estomatite Protética do Tipo II. Foi tratado com o reembasamento da prótese.

Tipo III: Inflamação granular ou hiperplásica papilar. A mucosa tem uma aparência nodular com hiperemia na superfície, sendo mais restrita à área central da mucosa palatina (fotografia 3 ).

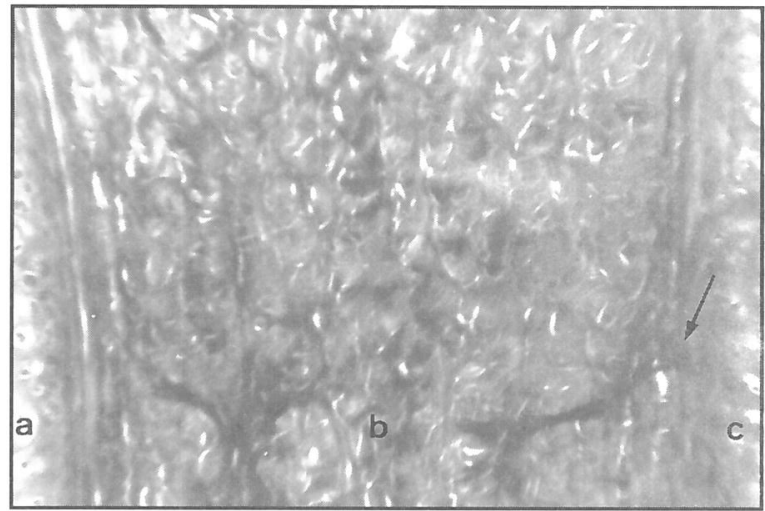

Fotografia. 3. Paciente do gênero feminino, com 48 anos apresentando Estomatite Protética do Tipo III. Foi tratada com a substituiçãa da prótese.

Uma vez classificados quanto à severidade da Estomatite Protética, os pacientes foram agrupados em dois grupos, e tratados de acordo com os seguintes protocolos:

\section{Grupo I}

Os pacientes deste grupo receberam ovas próteses. As próteses foram confeccionadas com a resina acrílica termopolimerizável da marca Clássico. 0 ciclo de polimerização adotado foi o proposto por PHILLIPS(1993).

Grupo II

Todas as próteses dos pacientes deste grupo foram ajustadas quanto à sua oclusão ou fatores de trauma e ainda reembasadas com Kooliner

A higienização das próteses para ambos os grupos era a mesma, constituindo-se na escovação diária, após as refeições, em um número mínimo de 3 vezes ao dia. A escovação se processou com o auxílio de uma escova dental de maciez média, água e um creme dental de baixa abrasividade ou sabão neutro, tanto na porção interna da prótese quanto na externa.

A desinfecção da base das próteses se processou através da imersão das mesmas numa solução com hipoclorito de sódio a $2,5 \%$ diluída, numa proporção de uma colher de sopa de hipoclorito comercial para um copo d'água, durante 2 horas/dia.

Os pacientes dos dois grupos foram orientados para dormir sem as próteses. Todos os pacientes foram esclarecidos e motivados para a cura da sua patologia. Para isso foram controlados quinzenalmente por 2 meses, a fim de avaliar a ação da terapêutica empregada e sua relação com a severidade do quadro clínico inicial da Estomatite Protética. Em ambos os grupos, ao longo de todo o acompanhamento, buscou-se identificar e corrigir possíveis traumas por oclusão, sobre extensão ou asperezas ainda presentes. Foi reforçada a importância de uma higiene bucal e da prótese e a necessidade da remoção durante à noite. Os resultados obtidos foram submetidos ao teste $t$ Student.

\section{RESULTADOS}

A mostra deste trabalho foi constituída por 30 pacientes com Estomatite Protética, sendo 3 pacientes homens $(10 \%)$ e 27 
pacientes mulheres (90\%) com uma idade que variou entre 31 e 76 anos.

Do total dos pacientes avaliados com Estomatite Protética vinte e um pacientes (70 \%) necessitavam substituir suas próteses maxilares, 9 pacientes (30\%) necessitavam substituir suas próteses duplas. Esta necessidade em relação ao tempo de uso das próteses variava entre 1 e 3 anos.

A maioria dos pacientes relatou o uso contínuo das próteses: 28 pacientes, $(93,33$ $\%)$. Somente 2 pacientes $(6,67 \%)$ relataram uso diurno das próteses totais.

Quanto à retenção e estabilidade dos aparelhos em boca, 1 (3,33\%) paciente apresentou condições excelentes, 8 pacientes $(26,66 \%)$ apresentaram retenção e estabilidade satisfatória e 11 pacientes (70 \%) mostraram condições insatisfatórias.

0 aumento da dimensão vertical foi notado em 4 pacientes (13,33\%), enquanto que 16 pacientes $(53,33 \%)$ apresentavam próteses com dimensão vertical normal. A diminuição da dimensão vertical foi observada em 10 pacientes $(33,34 \%)$.

Vinte e sete $(90 \%)$ declararam que não tomavam nenhum cuidado em especial quanto à limpeza da prótese.

A escovação, foi o método relatado por todos os pacientes para a higienização da prótese e ou cavidade bucal, o que variou foi o número de vezes e o auxílio ou não de um dentifrício. A higienização se processava após as principais refeições com uma escova dental e um dentifrício, eventualmente com sabão.

Quanto aos hábitos de higiene 2 pacientes $(6,66 \%)$ declararam que usavam bicarbonato de sódio na limpeza de suas próteses, 1 paciente $(3,34 \%)$ complementava a limpeza com o uso de bombril e saponácio.

A aspereza na superfície interna da prótese foi notada em 2 dos pacientes $(6,66$ $\%)$.

Quanto à queixa principal diversas foram as causas relatadas que levaram a buscar atendimento : Quatorze pacientes $(46,66 \%)$ relataram falta de retenção, 10 pacientes afirmaram que estavam insatisfeitos com a estética da prótese, 9 pacientes buscavam atendimento porque as próteses em uso estavam gastas, 3 pacientes solicitaram atendimento por fratura da prótese. Outras queixas tais como: dificuldade de mastigação, pigmentação, aumento da dimensão vertical, correção de hiperplasia, coceira no palato, dentes se desprendendo, falta de dentes antagonistas, trauma e prótese muito grande tinham menor prevalência. Vale salientar que alguns pacientes apresentavam mais de uma queixa simultânea.

Dezoito pacientes tiveram suas próteses totais substituídas por novas e em 12 pacientes foi realizado o reembasamento das próteses totais com Kooliner.

Onze pacientes $(36,66 \%)$ apresentaram Estomatite Protética do Tipo I de Newton, $13(43,33 \%)$ pacientes do Tipo II e $6(20 \%)$ do Tipo III.

A discrepância maior entre pacientes onde houve troca de prótese ou reembasamento ocorreu no grupo de pacientes com Estomatite Protética do Tipo II, pois neste grupo havia um número maior de próteses sem condições de uso, mesmo se fossem reembasadas.

Do total de pacientes submetidos a tratamento observou-se que em 27 pacientes (90\%) houve cura da Estomatite Protética durante um período de, no máximo 8 semanas, independentemente do tipo de tratamento indicado. Os 3 pacientes (10\%) que permaneceram com a lesão, mostraram diminuição no grau de severidade clínica da doença.

Os tempos experimentais deste estudo alcançaram até à $8^{\mathrm{a}}$. semana após a substituição da prótese ou do seu reembasamento. Podemos observar pela tabela 1 que o tempo médio de cura foi de aproximadamente 4 semanas independentemente do tipo de tratamento realizado. Este achado submetido ao teste t de avaliação de diferença entre métodos, mostrou-se não significante para valores de p inferiores a 0,05 . Vale dizer que as duas formas terapêuticas são eficazes para a cura da Estomatite Protética, sendo esta afirmação estatisticamente significante. Observa-se um maior percentual de cura em quatro semanas de tratamento sendo em casos de Estomatite Protética do Tipo I e II, notamos a ausência da cura completa em alguns pacientes.

No grupo da Estomatite Protética do Tipo III achamos cura mais lenta como reembasamento, porém houve cura completa em todos os casos tratados.

Convém salientar que o critério de cura nas Estomatites Protéticas do Tipo III era o desaparecimento das zonas eritematosas, ulceradas e/ou

\begin{tabular}{|l|c|c|c|}
\hline Tratamento & $\begin{array}{c}\text { Tempo } \\
\text { Médio } \\
\text { Cura em } \\
\text { Semanas }\end{array}$ & $\begin{array}{l}\text { Desvio } \\
\text { Padrão }\end{array}$ & $\mathrm{P}$ \\
\hline $\begin{array}{l}\text { Substituição } \\
\text { Reembasamento }\end{array}$ & $\begin{array}{c}4,7059 \\
4,6667\end{array}$ & 1,572 & 0,954 \\
\hline
\end{tabular}

pseudomembranosas, porém com persistência das áreas hiperplásicas.

Tabela 1 - Distribuição do tempo médio de cura de pacientes em semanas com Estomatite Protética submetidos ao reembasamento ou substituição das próteses (PUCRS - Porto Alegre, 1999).

\section{DISCUSSÃO}

Os pacientes que constituíram esta amostra eram desdentados superiores, que apresentavam sinais clínicos de Estomatite Protética. Todos foram submetidos a um questionário que buscou eliminar aqueles que apresentavam doenças de origem sistêmica que pudessem exacerbar o quadro clínico da Estomatite Protética, ou mesmo representar um complicador na interpretação do resultado, pois autores consultados afirmaram que doenças sistêmicas como Diabete, Imunodepress̃ão, antibióticos, corticóides, leucemia, desnutrição podem induzir o aparecimento de Candidíase na cavidade bucal WINNER(1969); BUDTZ-JÖRGENSEN \& BERTRAM(1970);

JÖRGENSEN(1974);

BUDTZ-

JÖRGENSEN(1981); B BUDTZJÖRGENSEN(1990); ALLEN(1992); JEGANATHAN(1992); LIMA, SILVEIRA e BIRMAN(1994).

Neste trabalho pode-se comprovar o que LOVE et al.(1967), MIKKONEN et al.(1984), DIAZ et al.(1989) e ZANETTI et al.(1996) já haviam publicado, que o número de pacientes com Estomatite Protética é maior no gênero feminino do que no gênero masculino. As mulheres provavelmente se preocupam mais com sua condição bucal do que os homens, e portanto buscam atendimento odontológico com mais frequiência.

Outra possível explicação é a maior preocupação das mulheres com a estética, o que leva as mesmas a resistirem à idéia da remoção da sua prótese durante algumas horas.

A classificação de Estomatite Protética proposta por NEWTON(1962) nos parece bastante confiável uma vez que foi possível avaliar 30 pacientes ao longo do período experimental e podermos enquadrar todos num dos 3 tipos propostos naquela classificação. Além disso também pudemos avaliar a evolução da severidade da Estomatite Protética com base nessa classificação. Vale a pena salientar que durante o período experimental observamos a evolução da Estomatite Protética e assim mesmo notamos a passagem de um grau superior para outro inferior sem saltos, o que confirma a propriedade da classificação em 3 níveis diferentes de severidade. 
GROS et al.(1990) observaram que em numerosas ocasiões a descoberta da Estomatite Protética ocorre através de um exame de rotina pelo cirurgião-dentista, devido à ausência da percepção da sintomatologia pelo paciente. Em nosso estudo as lesões de Estomatite Protética eram, segundo os pacientes, assintomáticas sendo constatadas pelo exame clínico.

DIAZ et al.(1989) notaram uma redução progressiva da Estomatite Protética a partir dos 49 anos, o que não se verificou em nosso estudo. Pode-se notar que as faixas etárias vão até 66-76 anos com um número de pacientes relativamente constante. $O$ estudo realizado por DIAZ apresentou um número de pacientes maior e foi realizado dentro de um grupo experimental mais heterogêneo, o que pode em parte explicar as diferenças com esta pesquisa. Devemos salientar sobretudo que os pequenos desajustes que se manifestam ao longo do tempo de uso da prótese podem contribuir com a etiologia da Estomatite Protética, e independem da idade do paciente, mas sim do tempo de uso das mesmas.

O uso contínuo das próteses totais é um hábito em nossa sociedade, possivelmente em função do constrangimento do indivíduo de apresentarse sem seus dentes perante outras pessoas, mesmo que próximas. Considerando-se a etiopatogenia da Estomatite Protética observa-se a ação sinérgica da infecção pela Cândida, os microtraumatismos provocados pelo uso contínuo da prótese e o acúmulo da placa depositada no aparelho e em contato com a mucosa bucal CATALAN(1981), TARBET(1982).

Ainda hoje há divergência entre os profissionais quanto à necessidade da remoção da dentadura durante a noite. SAIZAR(1972) entende que o paciente deve usar a prótese durante a noite, pelo menos durante a fase de adaptação. TADAKI(1989) aconselha a não dormir com a prótese, mas somente quando o paciente se acostumar integralmente a ela. Teme-se que a remoção freqüente da prótese dificulte a adaptação do paciente para com a mesmas, pois toda a prótese exige um período de adaptação e de ajustes, para que se conquiste o conforto esperado. A remoção freqüente dificulta a identificação dos locais de ajuste. WALKER, D.M. et al.(1981) entendem que a prótese deve ser removida à noite.

Neste estudo em ambos os grupos experimentais solicitou-se ao paciente a remoção da mesma à noite e tivemos resultado de cura num espaço de tempo relativamente curto. É nossa opinião de que a remoção das próteses por um periodo auxilia na cura e possivelmente prevenção da Estomatite Protética. Outra justificativa para a remoção das próteses por um período é devido à necessidade de controlar-se a infecção da base da prótese de forma mais eficiente pela imersão da mesma em soluções como a solução de hipoclorito de sódio a 2,5\% diluída em água. Embora a remoção da dentadura à noite reduza drasticamente a incidência da inflamação LOVE et al.(1967). O uso contínuo da dentadura dificulta a auto-higienização, reduz o fluxo salivar proporcionando a inflamação FELTRIN(1989).

Concordamos com DIAZ et al.(1989) quando dizem que "a ação patogênica dos transtornos por desajuste se expressa fundamentalmente por pequenos transtornos imperceptíveis ao paciente" . Em dois pacientes $(6,66 \%)$ observamos asperezas na superfície de acento da prótese. Em contrapartida 11 pacientes $(70 \%)$ apresentaram retenção e estabilidade insatisfatória, sem que isso despertasse a atenção dos pacientes para com a Estomatite Protética. $O$ atrito contínuo, mas imperceptível, contribui para uma agressão ao tecido de suporte da dentadura proporcionado à invasão tecidual por microorganismos, entre eles a Cândida.

ARIKAN et al.(1995) notaram que o efeito benéfico do tratamento da substituição da dentadura por outra mais ajustada só é eficaz na Estomatite Protética generalizada. Esta constatação é contrária aos achados deste estudo, uma vez que encontramos cura em $90 \%$ dos casos e melhora nos restantes $10 \%$ dos casos. Além disso devemos salientar que a cura ocorreu num espaço de tempo de aproximadamente 4 semanas.

FELTRIN(1989) observou que o acrílico termopolimerizável confeccionado segundo o que preconiza o fabricante e sem uso apresenta irregularidades e porosidades discretas, e que a superfície da resina da prótese de um paciente com Estomatite Protética aparecia quase que totalmente recoberta com placa densa. Somos favoráveis à associação da escovação com a desinfecção química, pois a desinfecção independe da capacidade motora do paciente, da motivação e da dificuldade de acesso a todas as áreas.

$O$ aumento da dimensão vertical de oclusão que poderia levar ao trauma da mucosa de suporte, teve incidência de $13,33 \%$ nos casos de Estomatite Protética tratados. $53,33 \%$ dos pacientes apresentavam dimensão vertical de oclusão normal e 33,34\% uma dimensão vertical de oclusão diminuída, isso nos leva a afirmar que a Estomatite Protética ocorre independentemente da variação da dimensão vertical de oclusão. Esta constatação não encontra respaldo na literatura.

Todos os pacientes relataram que higienizavam suas próteses através da escovação com dentifrício ou sabão após as refeições e no entanto manifestaram a Estomatite Protética. Este fato deixa claro que nestes casos a técnica foi ineficaz para prevenir o estabelecimento da Estomatite Protética, o que serve, mesmo que de maneira indireta para reforçar a afirmação de que a Estomatite Protética é uma lesão de etiologia multifatorial FONSECA(1980), DIAZ et al.(1989); JEGANATHAN(1992); FELTRIN et al.(1993); BARBACHAN et al.(1995).

Pacientes portadores de próteses totais, de um modo geral perderam seus dentes por falta de orientação, falta de motivação para a higienização ou por falta de habilidade técnica para a limpeza de seus dentes. A perda total dos dentes induz a pensar na não obrigatoriedade da higienização. Ao instalar-se um aparelho protético em qualquer paciente, é responsabilidade do cirurgião-dentista explicar a necessidade de cuidados de higiene e conservação com as próteses em uso.

Devemos nos preocupar ainda em confeccionar próteses sem porosidade, com papilas interdentais biconvexas e prótese com superfícies polidas para que o acúmulo de placa seja reduzido.

Com este trabalho buscamos comparar dois métodos de tratamento da Estomatite Protética que possibilitasse a cura através de uma técnica simples e de baixo custo e acessível. Buscamos, portanto, num grupo experimental substituir a prótese do paciente e em outro reembasar as próteses a fim de devolver a estabilidade, a retenção e a adaptação da mesma ao rebordo alveolar.

A tentativa de uso terapêutico de antifúngicos tópicos ou sistêmicos tem demonstrado resultados pouco animadores. BERGENDAL \& ISACSSON(1980) observaram que o tratamento da Estomatite Protética com antifúngico é ineficaz, a recolonização de leveduras ocorre após o término do tratamento. WATSON et al.(1982) entendem que o uso de nistatina e amfotericina B é satisfatório, no entanto admitem que alguns casos de Estomatite Protética não responde ao uso destes fármacos.

A esterilização por intermédio do microondas ainda não está ao acesso de todos os pacientes. 
Em 18 pacientes substituímos suas próteses totais por outras novas, e os outros 12 pacientes tiveram suas próteses ajustadas e reembasadas com Kooliner. Os pacientes foram orientados a higienizar suas próteses e desinfetá-las com um hipoclorito comercial.

Optamos pelo uso do material de reembasamento Kooliner, embora seja considerado de uso temporário (BUNCH, 1987), é de fácil aplicação, pois permite o reembasamento direto, uma duração compatível com o tempo de tratamento, permitindo novas correções.

Os resultados obtidos nos mostram que não há diferença estatisticamente significante entre os tratamentos de substituição e reembasamento da dentadura no tratamento da Estomatite Protética, uma vez que encontramos cura para o paciente em aproximadamente 4 semanas para a maioria dos pacientes.

O reembasamento pareceu ser a melhor solução, pois o procedimento é rápido, necessita apenas de uma consulta, é de fácil execução, menos complicado, de baixo custo e propicia uma adaptação mais rápida do paciente à prótese do que aqueles que substituíram suas dentaduras. No entanto, à medida que o acompanhamento foi se aproximando da $8^{\text {a }}$. semana notou-se que o material de reembasamento começava a se desprender, exigindo a sua correção ou substituição. Momento em que o paciente submetido à substituição da dentadura já havia se adaptado completamente à nova dentadura, não necessitando de ajustes complementares. Mesmo tendo curado a Estomatite Protética por intermédio do reembasamento da dentadura e pela desinfecção da mesma, ainda permanecem problemas naturais a uma dentadura de muitos anos de uso, como estética insatisfatória e: ou desprendimento de dentes, alteração da dimensão vertical de oclusão.

Parece mais conveniente em nossa opinião buscar a cura da Estomatite Protética pelo reembasamento e treinamento dos hábitos de uso essenciais para o uso de uma prótese dentária total, que se traduz pela sua remoção durante um período de tempo por dia, sua higienização e desinfecção a fim de diminuir a possibilidade de aparecimento da Estomatite Protética.

Foi possível constatar neste estudo, que a Estomatite Protética é uma doença multifatorial dependente do trauma, da placa e da má higiene, sendo necessária portanto, a correção de todos os fatores na abordagem terapêutica. Poder-se-ia sugerir como uma conduta clínica razoável o reembasamento da prótese total e o treinamento do paciente com realização da higienização e desinfecção das próteses por um período de 4 semanas. Após este período o cirurgião-dentista pode esperar a regressão completa da Estomatite Protética e então iniciar a fase de confecção da prótese nova.

\section{CONCLUSÕES}

Com base na metodologia empregada e nos resultados obtidos, foi possível concluir, na amostra estudada, que:

1. tanto o reembasamento da prótese total quanto à sua substituição, acompanhada dos métodos de desinfecção e higienização, são eficazes na cura da Estomatite Protética;

2. a cura ocorre em $90 \%$ dos casos, num prazo médio de 4 semanas;

\section{SUMMARY}

This clinic survey aimed at comparing two different treatments for patients using full upper denture and having clinical Denture Stomatitis diagnosis. Thirty patients were selected and divided into two groups. Group I included 18 patients, whose dentures were replaced by new ones. Group II included 12 patients, whose full dentures currently used were relined. Patients were followed-up during 8 weeks. Patients of both groups were required to remove their dentures at night to be disinfected with Sodium Hypochlorite solution. The results observed show Denture Stomatitis was cured within 4 weeks in $90 \%$ the cases for both groups, showing no significant statistical differences. It may be concluded that both dentures replacement and their filling, associated to hygiene and disinfection show efficacy in Denture Stomatitis control.

\section{KEYWORDS}

Denture stomatitis, full denture,

\section{REFERÊNCIAS BIBLIOGRÁFICAS}

1. ABELSON, D.C. Denture plaque and denture cleansers. J. Prosthet. Dent. Saint.Louis, v.45, n.4, p.376-379, Apr. 1981.

2. ALLEN, C.M. Diagnosing and managing oral candidiasis. J.Am.Dent.Assoc. Chicago, v.123, n. 1, p.77-78, 81-82. Jan. 1992.

3. APFELBAUM, D. Un nuevo concepto en cepillos para dentaduras artificiales. La Tribuna Odontol. v., 54, n.1, p.42-45, ene./mar. 1970.

4. ARAÚJO, N S.; ARAÚJO V.C. Patologia bucal. São Paulo: Artes Médicas 1984.
5. ARIKAN, A.; KULAK, Y.; KADIR, T. Comparison of different treatment methods for localized and generalized simple denture stomatits. J. Oral Rehabil. Oxford, v.22, n.5, p.365-369, May. 1995.

6. BACKENSTOSE, W.M.; WELLS, J.G. Side effects of immersion-type cleanser on the metal components of dentures. J. Prosthet. Dent., Saint.Louis, v.37, n.6, p.615-621, June 1977.

7. BALÁEZ, A.B.; DÍAZ, E.M. La respuesta inflamatoria celular em la estomatitis subprótesis. Rev. Cub. Estomatol., Havana, v.22, n.2, p.161-167, mayo./ago., 1985.

8. BARBACHAN, J.J.D. et al. Estudo clínico de estomatite protética: avaliação preliminar. Rev. Fac. Odontol. UFRGS. Porto Alegre, v.36, n.1, p.27-31, ago. 1995.

9. BAYSAN, A.; WHILEY, R.; WRIGHT, P. Use of microwave to disinfect a long-term soft lining material contaminated with Candida albicans or Staphylococcus aureus. J. Prosthet. Dent., St. Louis v.79, n.4, p. 454-458, Apr. 1998.

10. BERGENDAL T.; ISACSSON, G. A Effect of nystatin in the treatment of denture stomatitis. Scand. J. Dent. Res., Copehagen, v.88, n.5, p.446-454, Oct. 1980.

11. BERGENDAL T.; ISACSSON, G. A combined clinical, mycological and histological study of denture stomatitis. Acta. Odontol. Scand., Oslo, v.41, n.1, p.33-44, 1983.

12. BOUCHER, C.O.; HICKEY, J.C.; ZARB, G.A. Protesis para al desdentado total. Buenos Aires: Mundi, 1977. 610 p.

13. BUDTZ-JÖRGENSE, E.; BERTRAM, U. Denture stomatitis I. The etiology in relation to trauma and infection. Acta Odontol. Scand., Oslo, v.28, p.7192, 1970a.

14. BUDTZ-JÖRGENSE, E.; BERTRAM, U. Denture stomatitis II. The effect of antifungal and prosthetic treatment. Acta Odontol. Scand., Copenhagen, v.28, p.283-304, 1970b.

15. BUDTZ-JÖRGENSE, E.; LÖE, H. Chlorhexidine as a denture disinfectant in the treatment of denture stomatitis. Scand. J. Dent. Res., Copenhagen, v.80, p.457464, 1980.

16. BUDTZ-JÖRGENSE, E. The significance of Candida albicans in denture stomatitis Scand. J. Dent. Res., Copenhagen, v. 82, p.151-190, 1974.

17. BUDTZ-JÖRGENSE, E.; KELSTRUP, J. Enzymes as denture cleansers. Scand. J. Dent. Res., Copenhagen, v. 85, p. 209-215, 1977. 
18. BUDTZ-JÖRGENSE, E. A 3month's study of enzymes as denture cleansers. J. Oral Rehabil., Oxford, v. 5, n.1, p.35-39, Jan. 1978.

19. BUDTZ-JÖRGENSEN, E. Materials and methods for clening dentures. J. Prosthet. Dent., Saint.Louis, v.42, n.6, p.619-623, Dec. 1979.

20. BUDTZ-JÖRGENSEN, E. Oral mucosal lesions associated with the wearing of removable dentures. J. Oral Pathol. Med., Copenhagen, v.10, n.2, p.65-80, Apr.1981.

21. BUDTZ-JÖRGENSEN, E.; THEILADE, E.; THEILADE, J. Quantitative relationship between yeast and bacteria in denture-induced stomatitis. Scand J. Dent. Res., Copenhagen, v.91, n.2, p.134-142, Apr. 1983.

22. BUDZT-JÖRGENSEN, E. Etiology, pathogenesis, therapy, and prophylaxis of oral yeast infections. Acta Odontol Scand., Oslo, v.48, n.1, p.61-69, Feb. 1990.

23. BUNCH, J.; JOHNSON, G.H.; BRUDVIK, J.S. Evaluation of hard direct reline resins. J. Prosthet. Dent., St.Louis, v.57, n.4, p.512-519, Apr. 1987.

24. BURNS, D.R. et al. Response of processed resilient denture liners to Candida albicans. J. Prosthet. Dent., Saint.Louis, v.57, n.4, p.507-512, Apr. 1987.

25. CABRAL, L.A.G. Emprego da imunofluorescência direta no estudo das alterações de mucosa de palato, compatíveis com candidíase atrófica crônica, em indivíduos portadores de próteses dentária totais muco-suportadas. Rev. Odontol. UNESP, São Paulo, v.19, p.125-130, 1990.

26. CAHN, L.R. The denture sore mouth. J. Am. Dent. Ass. Chicago, v.3, p.33-36, 1936.

27. CATALÁN, S.A. Estomatitis subprotesis. Colonización microbiana de materiales bases em prótesis completas. Rev. Assoc. Odontol. Argent., Buenos Aires, v.69, n.3, p. 55-159, Mayo. 1981.

28. CATALÁN, A.; HERRERA, R.; MARTINEZ, A. Denture plaque and mucosa in denture stomatitis: scanning electron microscopic and microbiologic study. J. Prosthet. Dent., St.Louis, v.57, n.5, p.581-585, May. 1987.

29. CHASE, W.W.

Tissue conditioning utilizing dynamic adaptative stress. J. Prosthet. Dent., St.Louis, v.11, p. 804-815, Sept./Oct. 1961.

30. CAWSON, R.A. Denture sore mouth and angular cheilitis. Oral candidosis in adults. Br. Dent. J., London, v.115, n.11, p.441-449, Dec. 1963.
31. DANILEWICZ-STYSIAK, Z. Allergy as a cause of denture sore moth. J. Prosthet. Dent., St.Louis, v.25, p.1618, 1971.

32. DAVEVENPORT, J.C.; WILSON, H.J.; BASKER, R.M. The compatibility of tissue condictioner with denture cleaners and chlorhexidine. J. Dent., Kidlinton, v.6, n.3, p.239-246. Sept. 1978.

33. DENARDI, B.B. O uso da clorexidina na prática odontológica. Rev. da APCD, São Paulo, v.48, n.2, p.12791285, 1994.

34. DEVLIN, H.; WATTS, D.C. Acrylic "Alergy"? Brit. Dent. J., London, v.157, n.8, p.272-275, Oct. 1984.

35. DIAZ, E.M. et al. Estomatitis subprotesis: estudio epidemiologico en 6 302 pacientes portadores de protesis dentales removibles. Rev. Cub. Estomatol., Havana, v.26, n.1-2, p.71-80, ene./jun., 1989.

36. DOMITTI, S.S. et al. Prótese total novos métodos e técnicas. São Paulo: Santos, 1982, 140p.

37. DOTTO, C.A.; SENDYK, W.R. Atlas de higienização bucal. São Paulo: Panamed, 1982. p.87.

38. DOUGLAS, W.H.; WALKER, D.M. Nystatin in denture liners - an alternative treatment of denture stomatitis. Brit. Dent. J., London, v.135, p.55, 1973.

39. FELTRIN, P.P. Estomatite protética estudo da superfície interna da prótese total mucosuportada (microscopia eletrônica de varredura) e da mucosa bucal de suporte (citológico, histopatológico e imunohistoquímico). São Paulo, 1989. 72 p. Tese (Doutorado em Odontologia) - Faculdade de Odontologia, Universidade de São Paulo, 1989.

40. FELTRIN, P.P. et al. Estomatite protética: estudo da superfície interna da prótese total em microscopia eletrônica de varredura e da mucosa de suporte através de exame citológico, histopatológico e imunoistoquímico. Rev. Assoc. Bras. Odontol., Rio de Janeiro, v.1, n.1, jul./set., 1993.

41. FISHER, A.A. Allergic sensitization of the skin and oral mucosa to acrylic resin denture materials. J. Prosthet. Dent., St.Louis, v.6, p.593-602, Sept., 1956.

42. FONSECA, J.B. Candidíase. Aspectos de interesse odontológico. In: LACAZ, C.S. Prótese Dentária, São Paulo, Editora Pedagógica e Universitária, 1980. p.30-146.

43. GIUTA, J.; ZABLOTSKY, N.
Allergic stomatitis caused by selfpolymerizing resin. Oral Surg. Oral Med. Oral Pathol., Saint.Louis, v.41, n.5, p.631-637, 1976.

44. ZAMACONA-GROS, J.M. et al. Estomatitis Protética I. Aspectos clínicopatológicos y etiolpatológicos. Rev. Actual. Odontoestomatol. Esp., Madri, v.19 n.393, p.87-98, Mayo. 1990.

45. GRUBER, R.G.; LUCATORTO, F.M.; MOLANAR, E.J. Fungus growth on tissue conditioners and soft denture liners. J. Am. Dent. Ass., Chicago, v.73, p.641643, 1966.

46. GWINNETT, A.J.; CAPUTO, L.J. The effectiveness of ultrasonic denture cleaning: A scanning electron microscope study. J. Prosthet. Dent., St.Louis, v.50, n.1, p.20-25, July. 1983.

47. HEATH, J.R.; DAVENPORT, J.C.; JONES, P.A. The abrasion of acrylic resin by cleaning pastes. J. Oral Rehabil., Oxford, v.10, n.2, p.159-175, Mar. 1983. 48.HEIMDAHL, A.; NORD, C.A. Oral yeast infections in immunocompromised and seriously diseared patients. Acta Odontol. Scand., Oslo, v.48, n. 1, p. 77 84, Feb. 1990.

49. IACOPINO, A.M.; WATHEN, W.F. Oral candidal infection and denture stomatitis: a comprehensive review. J. Am. Dent. Assoc., Chicago, v.123, n.1, p.4651, Jan. 1992.

50.JAGGER, D.C.; HARRISON, A. Denture cleansing - the best approach. $\mathbf{B r}$. Dent. J., London, v.178, n.12, p.413-417, June 1995.

51. JEGANATHAN, S. Denture stomatitis - a review of the aetiology diagnosis and management. Aust. Dent. J., Sydney, v.37, n.2, p.107-114, Apr. 1992.

52. JORGE, A.O.C. et al. Estomatite por prótese total - presença de bactérias e fungos. Arq. Cent. Est. Curso Odontol. Belo Horizonte, Belo Horizonte, v.27, p.915, 1990.

53. KENG, S.; LIM, M. Denture plaque distribution and the effectiveness of a perborate-containing denture cleanser. Quintessence Int., New Malden, v.27, n.5, p.341-345, May, 1996.

54. KOOPMANS, A.S.F.; KIPPUW, N. Bacterial involvement in denture-induced stomatitis. J. Dent. Res. Alexandria, v.67, n.9, p.1246-1250, Sept., 1988.

55. KULAK, Y.; ARIKAN, A.; KAZAZOGLU E. Existence of Candida albicans and microorganisms in denture stomatitis patients. J. Oral Rehabil, Oxford, v.24, p.788-790, 1997.

56. LARA, E.H.G. et al. Avaliação laboratorial dos dentifrícios comerciais. 
Rev. ABO Nacional, Rio de Janeiro, v.4, n.3, p.176-183, jun./jul.,1996.

57. LEHNER, T. Oral candidosis. Dent. Rec., Bristol, v 17, n.6, p.209-216, Fev., 1967.

58. LIMA, O.C.C.; SILVEIRA, F.R.X.; BIRMAN, E.G. Manifestações bucais de origem infecciosa em pacientes HIVpositivos ou com Aids/I - Doenças fúngicas. Rev. ABO Nacional, Rio de Janeiro, v.2, n.1, p.28-32, fev./mar. 1994.

59. LOVE, W.D.; GOSKA, F.A.; MIXSON, R.J. The etiology of mucosal inflammation associated with dentures. J. Prosthet. Dent., Saint.Louis, v.18, n.6, p.515-527, 1967.

60. LOZANO-LUACES, V..; ESPIASGOMEZ, A.; MURTA-FERRE, J. Lesiones traumaticas de la mucosa oral provocadas por la presencia de protasis. Rev. Actual. Estomatol. Esp., Madri, v.46, n. 358, p.25-26, 29-30, set. 1986.

61. MacCALLUM, M. et al. Which cleanser? Dent. Pract. Dent. Rec, Bristol, v.19, n.3, p.83-89, 1968.

62. MACHADO, ADÃO R.L. Antifúngicos In: FUCHS, F.D.; WANNMACHER, L. Rio de Janeiro: Guanabara Koogan, 1992. Cap. 23, p. 241254.

63. MIKKONEN, M. et al. Prevalence of oral mucosal lesions associated with wearing removable dentures in Finnish adults. Comm. Dent. Oral Epidemiol., Copenhagen, v.12, n.3, p.191-194, June 1984.

64. MOTTA, L.G. et al. Análise do conteúdo abrasivo de dentifrícios. Rev. ABO Nascional, Rio de Janeiro, v.6, n.3, p.147-148, jun./jul. 1998.

65. NAIRN, R.I. Nystatin and amphotericin $\mathrm{B}$ in the treatment of denturerelated candidiasis. J. Oral Surg., Chicago, v.40, n.1, p.68-75, 1975.

66. NATER, J.P. et al. Etiologic factors in denture sore mouth syndrome. J. Prosthet. Dent., Saint.Louis, v.40, n. 4, p. 36\%-373. Dec. 1978.

67. NEALEY, E.T.; DEL RIO, C.E. Stomatitis venenata: reaction of patient to acritic resin. J. Prosthet. Dent., St.Louis, v.21, p.480-484. 1969.

68. NEILL. D.J. A study of materials and methods employed in cleaning dentures. Brit. Dent. J., London, v.124, n.3, p.107$115,1968$.

69. NEWTON, A.V. Denture sore mouth. A possible etiology. Brit. Dent. J., London, v.12, p.357-360, 1962.

70. NIKAWA, H., YAMAMOT, T.; HAMADA, T. Effect of components of resilient denture-lining materials on the growth, acid production and colonization of Candida albicans. J. Oral Rehabil., Oxford, v.22, n.11, p.817-824, Nov. 1995.

71. NYQUIST, G. The influence of denture hygiene and the bacterial flora on the condition of the oral mucosa in full denture cases. Acta Odontol. Scand. Oslo, v.1, p.24-60, 1952.

72. OLSEN, I. Denture stomatitis. Relapse tendency and removal of acquired discolourations in long-term denture desinfection with chlorhexidine. Acta Odontol. Scand., Oslo v.33, p.111-115, 1975.

73. OLSEN, I.; BIRKELAND, J.M Denture stomatitis - yeast occurrence and the $\mathrm{pH}$ of saliva and denture plaque. Scand. J. Dent. Res., Copenhagem, v.85, p.130-134, 1977.

74. PARANHOS, H.F.O.; MALACHIAS, A.; PARDINI, L.C. Materiais para limpeza de dentaduras: revisão da literatura. Rev. Fac. Odontol. Lins, São Paulo, v.4, n.2, p.19-24, 1991.

75. PHILLIPS, R.W. Skinner materiais dentários. 9 ed., Rio de Janeiro Guanabra Koogan, 1993. 334p.

76. PIPKO, D.J.; EL-SADEEK, M An in vitro investigation of abrasion and staining of dental resins. J. Dent. Res., Alexandria, v.51, p.689-705, 1972.

77. PRYOR, A. The cash problem. Brit. Dent. J., London, v.6 , p.284-285, 1936.

78. QUINN, D.M. The effectiveness, in vitro, of miconazole and keteconazole combined with tissue conditioners in inhibiting the growth of Candida albicans. J. Oral Rehabil., Oxford, v.12, n.2, p.177-182, Mar.1985.

79. RAAB, F.J. et al. Scanning electron microscopic examination of ultrasonic and effervescent methods of surface contaminant removal from complete dentures. J. Prosthet. Dent., St.Louis, v.65, n.2, p.255-258, Feb. 1991.

80. RUDD, R.W. et. al. Sterilization of complete dentures with sodium hypochlorite. J. Prosthet. Dent., Saint.Louis, v.51, n.3, p.318 -321, Mar. 1984.

81. SAIZAR, P. Prostodoncia total. Buenos Aires: Mundi,1972. 495p.

82. SANT'ANNA, A.T. et al. Higienização de prótese total pelo método mecânico. Odonto 9., v.2, n.3, p.280-285, set./out. 1992.

83. SCHLOSSER. R.O. ; GEHL, D.H.

Prothesis Completa. Buenos Aires: Mundi, 1957. $521 \mathrm{p}$.

84. SEXSON, J.C.; PHILLIPS, R.W. Studies on the effects of abrasives on acrylic resins. J. Prosthet. Dent., St.Louis, v.1, n.4, p.454-471, 1951.

85. SHARRY, J.J. Prostodoncia dental completa. Barcelona: Toray, 1977. $379 \mathrm{p}$.

86. TAMAKI, T. Dentaduras completas. 4 ed. São Paulo: Sarvier, 1983, $252 \mathrm{p}$.

87. TARBET, W.J. Denture plaque: quiet destroyer. J. Prosthet. Dent., St.Louis, v.48, n.6, p.647-652, Dec. 1982.

88. URIZAR,J.M.A et al. Estomatitis Protética II. Aspectos histológicos, diagnósticos y terapéuticos. Rev. Actual. Odontoestomat. Esp., Madri, v.50, n. 394, p.31-37, jun., 1990.

89. VAN REENEN, J.F. Microbiologic studies on denture stomatitis. J. Prosthet. Dent., St. Louis, v.30, n.4, p.493-505, 1973.

90. WALKER, D.M. et al. The treatment of denture-induced stomatitis. Evaluation of two agents. Brit. Dent. J. London, v.151, n.12, p. 416-419, Dec. 1981.

91. WEBB, B.C. et al. Effectiveness of two methods of denture sterilization. $\mathbf{J}$. Oral. Rehabil. v.25, n.6, p.416-423, June 1998.

92. WICTORIN, L. Effect of toothbrushing on acrylic resin veneering material. Acta. Odontol. Scand. Oslo, v.30, p.383-395, 1972

93. WILLIAMSON, J.J. Method of counting Candida albicans in saliva. $\mathbf{J}$. Dent. Res., Alexandria, v.47, n.6, p.979, Nov., 1968.

94. WINNER, H.I. The transition from commensalism to parasitism. Brit. J. Dermatol., Oxford, v.81, n.1, p.62-68, 1969.

95. WRIGHT, P.S. et al. Evaluating the effect of soft lining materials on the growth of yeast. J. Prosthet. Dent. St.Louis, v.79, n.4, p.404-409, Apr. 1998.

96. ZANETTI, R.V.; ZANETTI, A.L.; LAGANÁ, D.C.et al. P.P. Estudo de 60 pacientes de prótese parcial removível: Avaliação clínica das lesões nas áreas de suporte da mucosa. RPG. São Paulo, v.3, n.3, p.175-184, jul./ago./set. 1996.

Endereço para correspondência:

Pantelis Varvaki Rados

Av. Benjamin Constant

No: 1444 s/302 - Fone: 316.5011

e-mail: pantelis@vortex.ufrgs.br 